\title{
EFFECTS OF BASALT ON CORROSION RESISTANCE OF COMPOSITE BASALT-COPPER LASER CLADDING
}

\author{
Pavla Bartoň Klufová \& Antonín Kř̌́ž
}
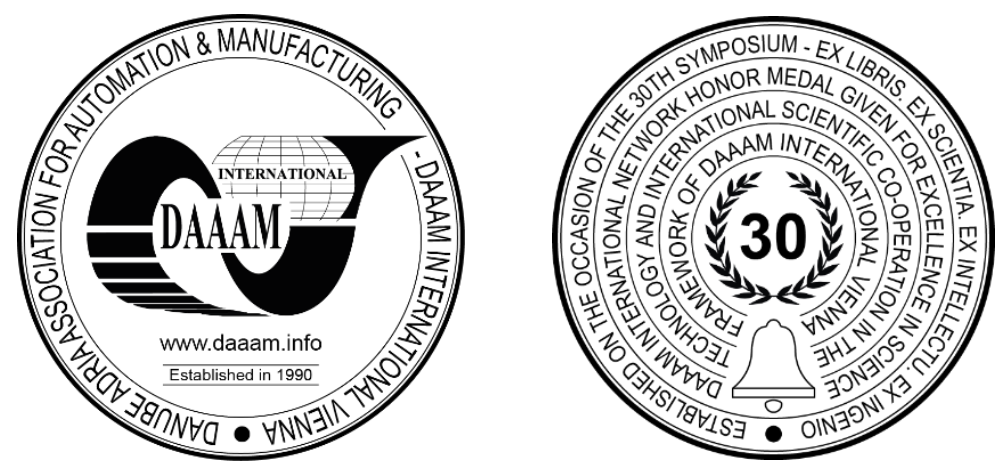

This Publication has to be referred as: Barton Klufova, P[avla] \& Kriz, A[ntonin] (2020). Effects of Basalt on Corrosion Resistance of Composite Basalt-Copper Laser Cladding, Proceedings of the 31st DAAAM International Symposium, pp.0746-0751, B. Katalinic (Ed.), Published by DAAAM International, ISBN 978-3-902734-29-7, ISSN 1726-9679, Vienna, Austria

DOI: $10.2507 / 31$ st.daaam.proceedings.103

\begin{abstract}
The present contribution explores the effects of basalt on corrosion resistance of basalt-copper composite material which has been deposited onto steel substrate by laser cladding. For this experimental study, three mixtures of filler powders were prepared, containing 15, 20 and 25 weight percent of basalt in Oerlicon METCO 55 powder $(\mathrm{Cu}>99.8 \%)$. With these powder mixtures, three specimens of composite laser overlays were prepared, each with a surface area of $100 \times 150 \mathrm{~mm}$. The substrate was S355 steel of $20 \mathrm{~mm}$ thickness. The impact of basalt on corrosion resistance of the composite was examined by metallographic techniques, optical microscopy and scanning electron microscopy. Local chemical compositions of these composite deposits were determined by means of EDX. The corrosion resistance of the copper-basalt composites was measured using the potentiodynamic corrosion test in artificial mine water electrolyte.
\end{abstract}

Keywords: Laser cladding; Composite; Copper; Basalt; Corrosion test

\section{Introduction}

Laser cladding relies on the high-energy-density laser beam to melt the base material as well as the cladding material. The latter may be in the form of powder or wire. The cladding process produces a narrow region, in which the melted cladding material and base material become metallurgically bonded. Their solidification thus leads to metallurgical bonds which provide the deposit with good cohesion as well as adhesion to the base material. The joint between laser overlay and substrate is usually the strong and are thus particularly appropriate for applications with heavy wear conditions (e.g. surface of marine crankshaft). The goal of laser cladding is to create an overlay with desired properties and chemical composition on the base material without extensive dilution (>10\%) between the two metals [1], [2].

Laser cladding finds primary use in the following broad areas:

- creation of new surfaces with pre-defined properties (resistance to abrasive wear, corrosion resistance in specific environments etc.),

- repair of parts (building up locations of minute casting defects by welding, repairs of worn surfaces of worm screws, digging buckets and other equipment). 
Because the surface of the clad is relatively rough, it needs to be post processed to achieve the required tolerance and a smooth surface. This is usually done with milling or grinding. The rough surface is sometimes welcome, usually when producing implants [3].

A number of industrial companies on the global market manufacture filler powders for laser cladding (Höganäs, Sandvik, Sulzer, Castolin Eutectic and others). As the supply of powders is governed by the demand from industrial users, the filler powders which are available on the market are those which are applied most often $(316 \mathrm{~L}$ stainless steel, Inconel 625 nickel alloy, Stellite 6 and Stellite 21 cobalt alloys, for instance). Where specific functional properties of a laser overlay are required, it becomes necessary to modify the commercially available filler powders or their mixtures to obtain a filler material with the appropriate chemical composition which can provide the desired properties of the overlay.

One of today's pressing issues discussed across the globe is the storage of spent nuclear fuel and high-level radioactive waste containers in underground repositories. Four storage container models have been proposed so far. Their sandwich structures are designed to contain the radiation from the spent nuclear fuel and high-level waste [4]. At the same time, the outer surface of these storage containers will be exposed to corrosive factors and degradation. These must be minimized. The Czech Republic maintains collaboration with many European countries which plan to build underground repositories for storage containers with high-level radioactive waste or spent nuclear fuel. A well-known solution is a Swedish storage container which comprises a two-layer jacket of copper (50 mm in thickness) and stainless steel [5], [6].

The need for corrosion protection of the outer surface of storage containers provides the scientific community and materials engineers with an impetus for seeking and developing new types of materials and surface treatments which deliver high level of corrosion protection.

\section{Material and Methods}

The experiments below have been proposed as part of development of a new copper-basalt composite material with high corrosion resistance in a non-aggressive environment (artificial mine water). The goal of these experiments was to deposit a laser overlay of copper-basalt composite material onto a substrate of S355 steel. Metallographic analysis and corrosion testing were proposed for assessing the synergistic effects of copper and basalt which have been observed in earlier research studies [7]. The base material for laser cladding was S355 steel plates of $20 \mathrm{~mm}$ thickness ground on both faces. The chemical composition of S355 steel as declared by the manufacturer is given in Table 1.

\begin{tabular}{|c|c|c|c|c|c|c|}
\hline $\mathbf{F e}$ & $\mathbf{C}$ & $\mathbf{S i}$ & $\mathbf{M n}$ & $\mathbf{C r}$ & $\mathbf{P}$ & $\mathbf{S}$ \\
\hline Balance & $0.42-0.50$ & $<0.40$ & $0.50-0.80$ & $<0.40$ & $<0.045$ & $<0.045$ \\
\hline
\end{tabular}

Table 1. Chemical composition of C45 steel, element content in weight per cent [8]

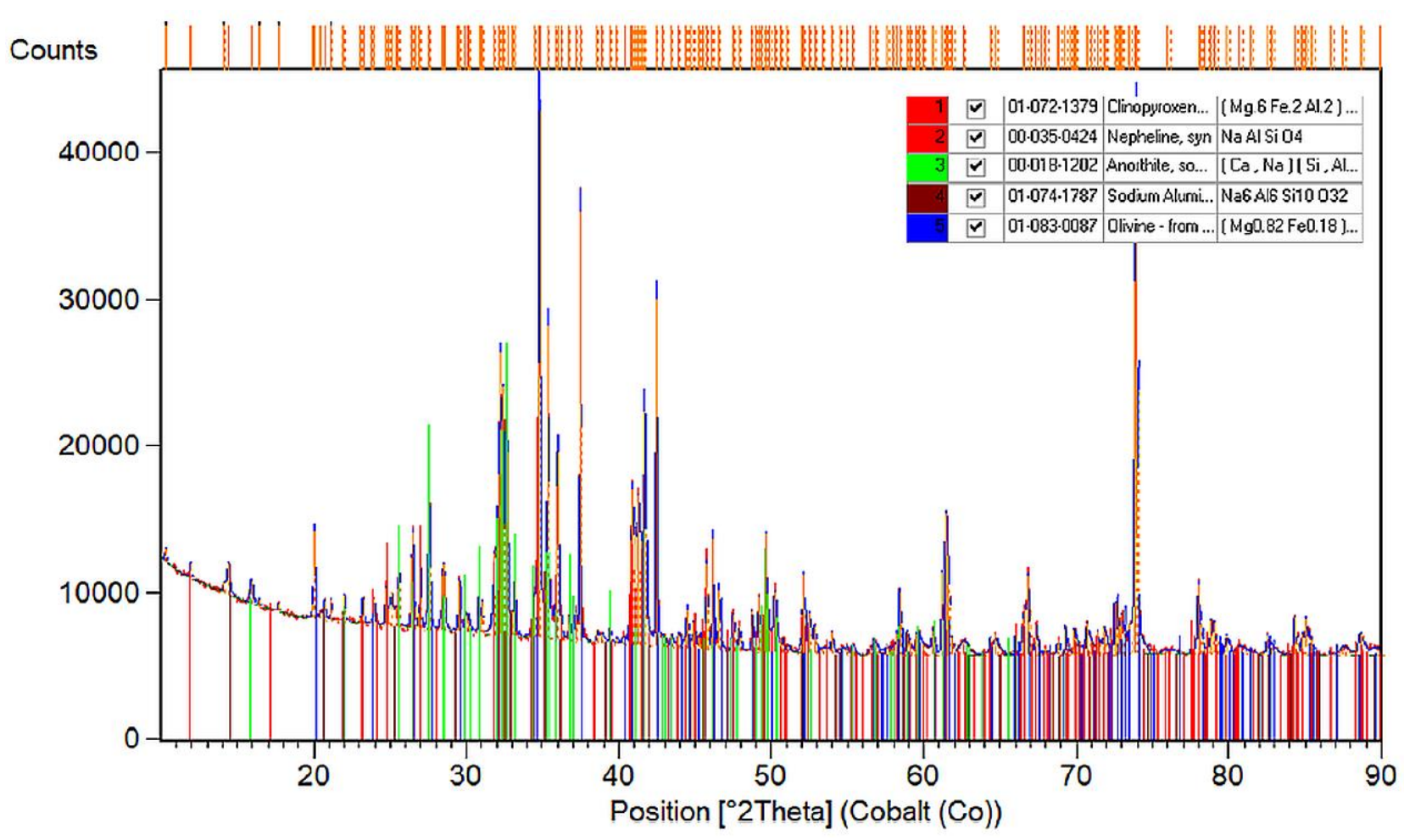

Fig. 1. Results of quantitative phase analysis of basalt dust 
The filler material that made up the matrix of the composite laser overlay was high-purity copper powder supplied by Oerlikon Metco under the brand name METCO 55. The copper level in METCO 55 was > 99\% and the particle size was 45-90 $\mu \mathrm{m}$. Manufacturer specifications of this powder are listed in Table 2.

\begin{tabular}{|c|c|c|c|c|}
\hline Copper content & Powder particle size & Morphology & Melting point & Density \\
\hline $\mathrm{Cu}$ min. $>99 \%$ & $45-90 \mu \mathrm{m}$ & Spherical & $1083^{\circ} \mathrm{C}$ & $3-4 \mathrm{~g} / \mathrm{cm}^{3}$ \\
\hline
\end{tabular}

Table 2. Oerlikon METCO 55, copper powder [9]

The filler for the composite powder was basalt dust supplied by the company Eutit, s.r.o. Using foundry screens, the 50-100 $\mu \mathrm{m}$ fraction was separated from the basalt dust and used for preparing the copper-basalt mixture for laser cladding. The phase composition of the basalt dust was determined with the aid of X'Pert Pro MPD instrument with Bragg-Brentano geometry. The diffraction pattern data was processed using X'Pert HighScore Plus software. Fig. 1 presents quantitative phase analysis data for a sample of the basalt dust supplied.

Table 3 gives a summary of the basalt dust phase composition and mass fractions of the identified phases.

\begin{tabular}{|c|c|c|c|c|c|}
\hline Identified phase & Clinopyroxene & Olivine & Nepheline & Anorthite & $\begin{array}{c}\text { Sodium } \\
\text { silicoaluminate }\end{array}$ \\
\hline Weight \% & 40 & 23 & 6 & 28 & 3 \\
\hline
\end{tabular}

Table 3. Phase composition of basalt dust and mass fractions of its phases

Three mixtures were prepared by combining Oerlikon METCO 55 and the basalt dust in the laboratory and used for depositing three composite copper-basalt overlays. The mixtures had different mass fractions of basalt in the Oerlikon METCO 55 powder:

- Mixture A (15 wt. \% basalt +85 wt. \% copper) $\rightarrow \quad$ Laser overlay SAMPLE A

- Mixture B (20 wt. \% basalt +80 wt. \% copper) $\rightarrow \quad$ Laser overlay SAMPLE B

- Mixture C (25 wt. \% basalt +75 wt. \% copper) $\rightarrow \quad$ Laser overlay SAMPLE C

The samples were made using solid-state disc laser Trumpf TruDisk 8002. Its wavelength was $\lambda=1030 \mathrm{~nm}$ and the spot size was $=3.4 \mathrm{~mm}$. The laser cladding powder mixture was fed via powder feeder GTV PF $2 / 2 \mathrm{MH}$ to coaxialfeeding cladding head Precitec YC52 with a four-beam nozzle. The assist and shielding gas was 5.0-purity argon [1]. The overlap between the laser tracks was $30 \%$ of a single track width. The area of each composite laser overlay was $100 \times 150 \mathrm{~mm}$.

\section{Metallographic Examination}

Metallographic characterisation of the overlays was performed using optical and scanning electron microscopy (SEM). SAMPLES A, B and C were sectioned in the transverse direction and the surfaces were prepared for metallographic examination and etched with Robin's reagent. The chemical composition of this etchant is described in [10].

Fig. 2 is a macrograph of a transverse section through SAMPLE A laser overlay. In Fig. 2, the fusion boundary between the composite laser overlay and the S355 steel substrate is clearly identifiable. No defects in the form of cracks or pores were found on the fusion boundary. Porosity in the overlay in Fig. 2 was quantified by means of Axiovision image analysis software and Carl Zeiss Z1M microscope. In SAMPLE A, the porosity level was $<5 \%$ of the total area under evaluation (the area shown in Fig. 2).

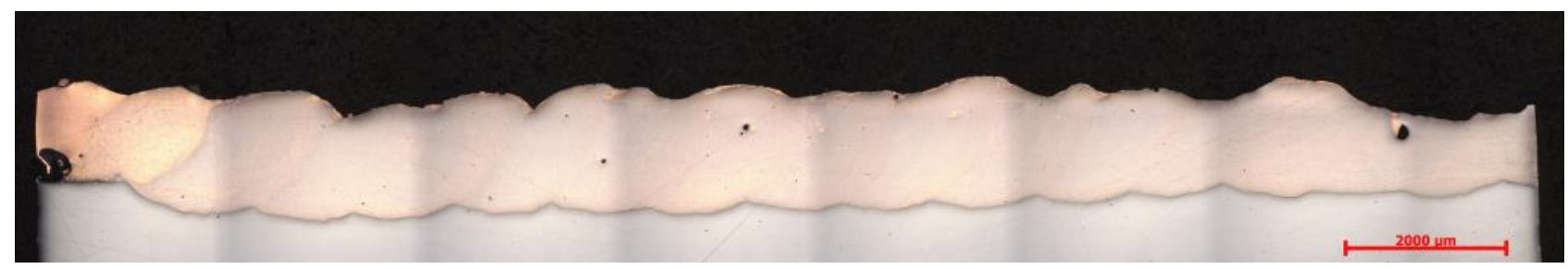

Fig. 2. SAMPLE A - Macrograph of a transverse section through the laser overlay; unetched; magnification 25× 
Metallographic analysis of SAMPLES A, B and C using Carl Zeiss Z1M optical microscope revealed substantial chemical and structural heterogeneity of the composite copper-basalt laser overlays. Fig. 3 shows cellular dendritic structure of the laser overlay in SAMPLE A (15 wt. \% basalt +85 wt. \% copper) at $50 \mu \mathrm{m}$ below its surface. A similar cellular dendritic structure was found in the sub-surface region of laser overlays in SAMPLES B and C. Farther from the overlay surface and towards the fusion boundary, the structure of the copper-basalt composite was developing whose matrix consisted exclusively of high-purity copper (see Fig. 4). Fig. 4 also shows a dispersion of the composite filler particles in SAMPLE C in an overlap region between two laser beads and in the vicinity of the fusion boundary between the laser overlay and the substrate.

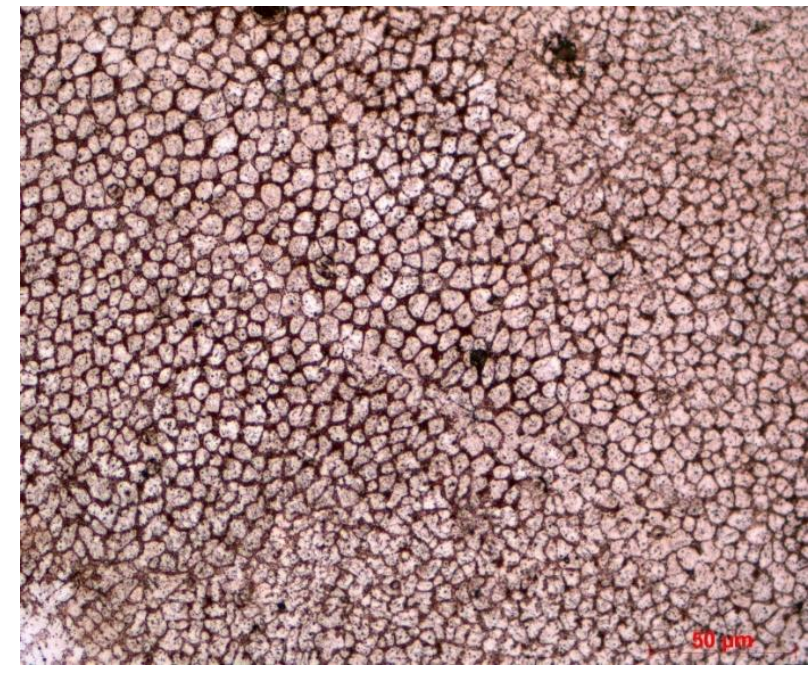

Fig. 3. SAMPLE A - Cellular dendritic structure in the surface of the laser overlay; etched with Robin's reagent; magnification $500 \times[11]$

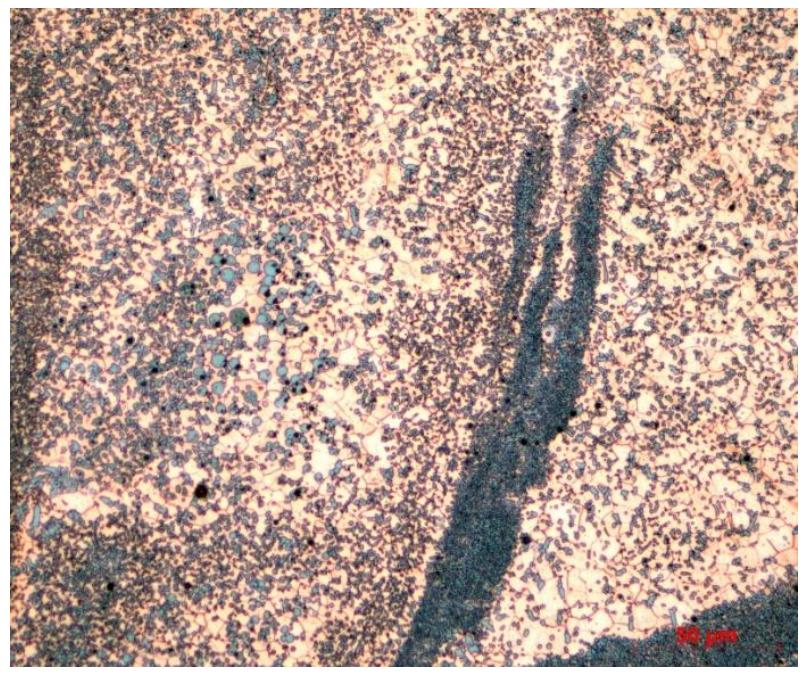

Fig. 4. SAMPLE C - Metallographic structure of the transition region between two beads; etched with

Robin's reagent; magnification 500× [11]

Microstructure of the composite copper-basalt laser overlays was examined in Philips XL 30 ESEM microscope and EDX analyser. Fig. 5 shows cellular dendritic structure of the laser overlay in SAMPLE B (20 wt. \% basalt + $80 \mathrm{wt}$. $\%$ copper) at $100 \mu \mathrm{m}$ below the surface of the laser overlay in the direction towards the fusion boundary. Three locations of EDX measurement of chemical composition are indicated in Fig. 5:

- EDX-M1 - this chemical composition measurement involved the entire area of Figure 5,

- EDX-M2 - chemical analysis of interdendritic spaces,

- EDX-M3 - chemical analysis of a cellular dendrite.

The measured chemical composition is clearly shown in Tab. 4. In SAMPLE B, the EDX-M1 area analysis detected mainly iron and copper in the composite laser overlay. Furthermore, EDX-M1 identified energy spectra of Si, Ca, Na, Al, $\mathrm{Mg}, \mathrm{Ti}, \mathrm{K}$ and $\mathrm{O}$. This confirms the presence of complex basalt oxides in a composite copper-basalt laser overlay. Although the SAMPLE B powder contained $20 \mathrm{wt}$ \% basalt $+80 \mathrm{wt}$ \% copper, EDX-M1 showed much less copper in the laser overlay (58.3 wt. \%). The reason for the lower amount of copper in SAMPLE B overlay is dilution which is inherent in laser cladding and in the process of formation of the metallurgical bond between the laser overlay and the substrate. In chemical analysis of interdendritic spaces EDX-M2, only the presence of $\mathrm{Cu}, \mathrm{Fe}$ and $\mathrm{O}$ was detected. According to EDX-M3 the cellular dendrite consisted primarily of copper and complex oxides in the basalt filler.

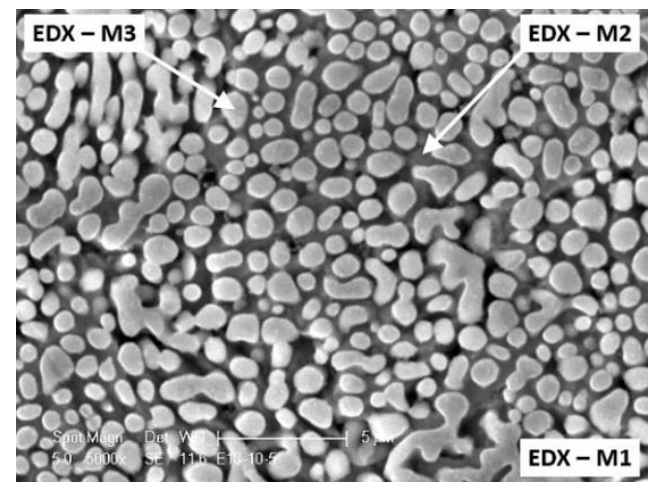

Fig. 5. SAMPLE B - Cellular dendritic structure in the surface of the laser overlay; etched with Robin's reagent; magnification $5000 \times$, scanning electron micrograph 


\begin{tabular}{|c|c|c|c|c|c|c|c|c|c|c|}
\hline & Fe & Cu & Si & Ca & Na & Al & Mg & Ti & K & O \\
\hline EDX - M1 & 2.3 & 58.3 & 6.7 & 5.2 & 7.8 & 2.2 & 6.9 & 2.0 & 1.1 & 7.5 \\
\hline EDX - M2 & 7.7 & 89.7 & - & - & - & - & - & - & - & 2.6 \\
\hline EDX - M3 & 22.3 & 62.5 & 2.8 & 0.6 & 0.3 & 0.2 & 5.9 & 0.5 & 1.0 & 3.9 \\
\hline
\end{tabular}

Table 4. SAMPLE B - Chemical composition measured by EDX in a scanning electron microscope

\section{Corrosion test}

Corrosion resistance of the composite laser clads was assessed using potentiodynamic corrosion testing with the aid of BioLogic SP-150 potentiostat. EcLab 10.44 software was employed for data processing and evaluation. First, the time dependence was measured of the steady-state corrosion potential between WE - WORKING ELECTRODE and RE REFERENCE ELECTRODE. The time for stabilization of free corrosion potential was identical in all measurements $\mathrm{t}_{\mathrm{R}}=30 \mathrm{~min}$. The, linear polarization was used for finding the dependence of corrosion current (converted to current density) on the mixed corrosion potential of the sample within the range from $E_{i}$ to $E_{L}\left(\mathrm{E}_{\mathrm{i}}=\mathrm{E}_{\mathrm{corr}}-0.025[\mathrm{~V}] ; \mathrm{E}_{\mathrm{i}}=\mathrm{E}_{\text {corr }}+\right.$ 0.025 [V]) with respect to the reference electrode $(R E)$. The Tafel lines obtained were extrapolated using the software EcLab 10.44 and the polarisation resistance $R_{p}[\mathrm{mV}]$ and corrosion rate $v_{\text {corr }}[\mu \mathrm{m} /$ year] were determined [1]. The electrolyte used for measuring the corrosion resistance of the composite weld clad/base material system was artificial mine water. Its chemical composition and method of preparation are described in [11]. Before the corrosion resistance of composite copper-basalt laser overlays was measured, the surfaces of the samples were lightly ground to produce appropriate flat regions for attaching a corrosion cell kit. On each of the SAMPLES A, B and C, ten potentiodynamic measurements of corrosion resistance were taken. The locations of measurements were distributed uniformly across the laser overlay. The reference specimen for comparing the corrosion resistance of the composite copper-basalt laser overlays in artificial mine water was high-purity $\mathrm{C} 10100$ copper sheet. The following Table 5 contains one representative set of measured and processed data from potentiodynamic testing for each laser overlay (SAMPLES A, B and C). Table 6 lists measured and processed corrosion rates for SAMPLES A, B and C and the C10100 copper reference specimen as mean values from ten measurements. In SAMPLE A ( $15 \mathrm{wt}$. \% basalt $+85 \mathrm{wt}$. \% copper), the mean corrosion rate was $\mathrm{v}_{\text {corr }}$ $=0.019 \pm 0.003\left[\mu \mathrm{m} /\right.$ year] . In SAMPLE B $(20 \mathrm{wt} . \%$ basalt $+80 \mathrm{wt} . \%$ copper $)$, the corrosion rate was $\mathrm{v}_{\text {corr }}=0.213 \pm$ $0.020\left[\mu \mathrm{m} /\right.$ year] and in SAMPLE C it was $\mathrm{v}_{\text {corr }}=0.594 \pm 0.128[\mu \mathrm{m} /$ year]. The potentiodynamic corrosion test data shows that with increasing addition of basalt in the filler powder for laser cladding Oerlikon METCO 55, the corrosion resistance of the composite laser overlay in artificial mine water decreases.

\begin{tabular}{|c|c|c|c|c|}
\hline Designation of sample & $\begin{array}{c}\text { Corrosion potential } \\
\mathbf{E}_{\text {corr }}[\mathbf{m V} \text { vs RE] }\end{array}$ & $\begin{array}{c}\text { Polarisation resistance } \\
\mathbf{R}_{\mathbf{p}}[\mathbf{\Omega}]\end{array}$ & $\begin{array}{c}\text { Polarisation } \\
\text { resistance.S }\left[\mathbf{\Omega . c m} \mathbf{2}^{\mathbf{2}}\right]\end{array}$ & $\begin{array}{c}\text { Corrosion rate } \\
{[\boldsymbol{\mu m} / \mathbf{y e a r}]}\end{array}$ \\
\hline SAMPLE A & -520 & 8752000 & 14373200 & 0.022 \\
\hline SAMPLE B & -479 & 9310000 & 16407900 & 0.179 \\
\hline SAMPLE C & -535 & 7996200 & 14251500 & 0.630 \\
\hline
\end{tabular}

Table 5. Potentiodynamic corrosion test; measured and calculated steady-state corrosion potential, polarisation resistance and corrosion rate; an example of measured data for SAMPLES A, B and C

\begin{tabular}{|c|c|c|}
\hline Designation of sample & $\begin{array}{c}\text { Mean corrosion } \\
\text { rate }[\boldsymbol{\mu m} / \mathbf{y e a r}]\end{array}$ & $\begin{array}{c}\text { Corrosion rates and standard } \\
\text { deviations [ } \boldsymbol{\mu} \text { //year] }\end{array}$ \\
\hline SAMPLE A (15 wt. \% of basalt + 85 wt. \% of copper) & 0.019 & $0.019 \pm 0.003$ \\
\hline SAMPLE B (20 wt. \% of basalt + 80 wt. \% of copper) & 0.213 & $0.213 \pm 0.020$ \\
\hline SAMPLE C (25 wt. \% of basalt + 75 wt. \% of copper) & 0.594 & $0.594 \pm 0.128$ \\
\hline Cu sheet (C10100) & 0.023 & $0.023 \pm 0.007$ \\
\hline
\end{tabular}

Table 6. Potentiodynamic corrosion test; corrosion rates in SAMPLES A, B and C and in C10100 copper sheet reference standard, mean values from ten measurements

\section{Limitations and future research plans}

In the present experiments, only three powder mixtures for laser cladding have been used. They had different mass fractions of basalt in METCO 55 copper powder. In order to characterize the effect of basalt on the corrosion resistance of basalt-copper composite laser overlay accurately, future research effors should follow the same strategy and involve more specimens of composite laser overlays with different ratios of copper and basalt in the powder mixtures. 
In addition, corrosion testing of copper-basalt laser overlays will have to be performed in a corrosion testing chamber by condensation of water to assess the impact of the corrosive medium on the surface of laser overlays. One major unknown aspect is the phase composition of the basalt powder since this igneous rock may contain, besides the phases listed in Table 3, a number of other complex oxide phases whose impact on the corrosion resistance of copper-basalt composite laser overlays has not yet been explored.

\section{Conclusions}

Using laser cladding, three experimental samples of composite copper-basalt overlays were prepared. SAMPLES A, $\mathrm{B}$ and $\mathrm{C}$ had different mass fractions of basalt in Oerlikon METCO 55 filler powder $(\mathrm{Cu}>99 \%)$. The base material for laser cladding was S355 steel plates ground on both faces. The surface area of each of the composite laser overlays was $100 \times 150 \mathrm{~mm}$. Metallographic specimens of the composite laser overlays were examined using optical and scanning electron microscopes. Their chemical composition was measured in pre-defined locations by EDX analyser in an SEM. The metallographic structure of SAMPLES A, B and C comprised predominantly cellular dendrites. Close to the fusion boundary between the laser overlay and the substrate, crystalline matrix consisting of high-purity copper and a dispersion of basalt particles was found. The corrosion resistance of laser overlays in artificial mine water was measured using the potentiodynamic corrosion test. The reference specimen for comparing the measured corrosion rates of the composites was C10100 copper sheet. Based on the results in Table 6, a conclusion may be drawn that with increasing amount of basalt in the laser cladding powder Oerlikon METCO 55, the corrosion resistance of the resulting laser overlay decreases. Using potentiodynamic corrosion testing, the lowest corrosion rate was found in SAMPLE A, in which $\mathrm{v}_{\text {corr }}=0.019 \pm$ $0.003[\mu \mathrm{m} / \mathrm{year}$. A comparison between the corrosion rates of the $\mathrm{C} 10100$ reference specimen and SAMPLE A shows that the presence and certain amount of basalt (specifically: $15 \mathrm{wt} . \%$ basalt) in the powder mixture for laser cladding improves oxidation resistance in this particular environment.

\section{Acknowledgments}

The above findings and results were achieved thanks to funding from the grant scheme of the University of West Bohemia - Motivation Scheme POSTDOC 2020.

\section{References}

[1] Klufová, P. (2018). Degradation of austenitic laser overlays. Ph.D. Dissertation, Department of material science and technology, Faculty of Mechanical engineering, University of West Bohemia, Pilsen, Czech Republic

[2] Torims, T., Vilcans, J., Zarins, M. \& Ratkus, A. (2012). Development of the in-situ laser renovation technology for marine diesel engine crankshafts, Proceedings of the 23rd International DAAAM Symposium, ISSN 2304-1382, ISBN 978-3-901509-91-9, Katalinic, B. (Ed.), pp. 0009-0014, Published by DAAAM International, Vienna, Austria

[3] Lestan, Z., Brezocnik, M., Milfelner, M. \& Balic, J. (2012). Laser Cladding in the Tooling Industry, Chapter 04 in DAAAM International Scientific Book 2012, pp. 045-052, B. Katalinic (Ed.), Published by DAAAM International, ISBN 978-3-901509-86-5, ISSN 17269687, Vienna, Austria, DOI: 10.2507/daaam.scibook.2012.04

[4] International Atomic Energy Agency. (2019). Demonstrating performance of spent fuel and related storage system components during very long term storage, Final report of coordinated research project, IAEA - Techdoc -1878 , Vienna, Austria, Available from: https://www-pub.iaea.org/MTCD/Publications/PDF/TE-1878web.pdf, Accessed on: 2020-10-05

[5] Underground repositories for spent nuclear fuel. (2019). Radioactive waste repository authority. Available from: https://www.surao.cz/wp-content/uploads/2019/09/surao_brozuraHU_online.pdf, Accessed on: 2020-07-12

[6] Interim storage facility, encapsulation plant and final repository for spent nuclear fuel. (2008). Background material for consultations according to the Espoo (EIA) Convention, Solna, Sweden, Available from: http://www.skb.com/wp-content/uploads/2015/06/Dokument-D-Background-material.pdf, Accessed on: 2020-0922

[7] Bartoň Klufová, P., Kříž, A., Vostřák, M. (2019). Development of laser clads with high corrosion resistance for nuclear power industry, AIP Conference Proceedings 2189, Pilsen, ISSN 0094-243X, ISBN 978-0-7354-1936-0, pp. 020011-1 - 020011-8, American institute of physics Inc., Maryland, DOI 10.1063/1.5138623

[8] Datasheet of C45 steel. (2019). Available from: www.bolzano.cz, Accessed on: 2020-10-01

[9] Oerlikon Metco. (2018). Datasheet of copper powder - Metco 55, Available from: https://www.oerlikon.com/, Accessed on: 2020-06-28

[10] Davis, J. R. \& Associates. (2001). Copper and copper alloys, ASM Speciality handbook,ASM International, ISBN 0-87170-726-8, United States of America

[11] Tittel, J. (2019). Testing of corrosion resistance of composite laser overlays with long half-life, Diploma thesis, Department of material science and technology, Faculty of Mechanical engineering, University of West Bohemia, Pilsen, Czech Republic 